\title{
Transcriptional Analysis of Host Responses to Marek's Disease Virus Infection in Chicken Thymus
}

\author{
Xuming Hu ${ }^{b}$ Aijian Qin ${ }^{a-c}$ Wencai Xu ${ }^{b}$ Genghua Wu ${ }^{a}$ Dan Li ${ }^{b}$ Kun Qian ${ }^{a}$ b \\ Hongxia Shao $^{a, b}$ Jianqiang Ye $\mathrm{e}^{\mathrm{b}, \mathrm{c}}$ \\ ${ }^{a}$ Key Laboratory of Jiangsu Preventive Veterinary Medicine and ${ }^{b}$ Ministry of Education Key Lab for Avian Preventive \\ Medicine, Yangzhou University, and ' Jiangsu Co-Innovation Center for Prevention and Control of Important Animal \\ Infectious Diseases and Zoonoses, Yangzhou, PR China
}

\section{Key Words}

Marek's disease virus · Chicken · Thymus · Microarray

\begin{abstract}
Marek's disease virus (MDV) is a cell-associated alpha-herpesvirus that causes T-cell lymphomas and nervous disorders in chickens. Different from other lymphoid organs, the thymus is the site of T-cell maturation and differentiation. However, the transcriptional response to MDV infection in the chicken thymus is still not known. In this study, we performed genome-wide expression analysis in thymus tissues of RB1B-infected chickens at different time points to investigate the molecular mechanisms of MDV pathogenesis. The number of differentially expressed genes with 2 -fold or higher changes ( $>2$ ) are as follows: 1,250 genes ( $7 \mathrm{dpi}), 834$ genes (14 dpi), 1,958 genes (21 dpi), and 2,306 genes ( $28 \mathrm{dpi}$ ). Gene ontology enrichment analysis revealed that the upregulated genes were involved in immune and inflammatory response at $7 \mathrm{dpi}$; angiogenesis, cytoskeleton organization, cell adhesion, and signal transduction showed different expressions at 21 and $28 \mathrm{dpi}$. The expression pattern of 18 randomly selected genes was confirmed by real-time RT-PCR. Several differently expressed host genes associated with tumor development are discussed. We identified the global host-gene
\end{abstract}

expression pattern in the thymus of chickens that responded to MDV infection. The present data may provide groundwork for future investigation in the biology and pathogenesis of MDV.

(c) 2015 S. Karger AG, Basel

\section{Introduction}

Marek's disease is a lymphoproliferative disease in domestic chickens caused by a highly oncogenic, cell-associated alpha-herpesvirus termed Marek's disease virus (MDV) [1]. MDV infection in chicken induced T-cell lymphomas. The thymus, unique among lymphoid organs, is where T cells mature and differentiate. Severe atrophy of the thymus is found in MDV-infected chickens. This indicates that MDV does not destroy cell-mediated immune but certain cells of the system (e.g. CD4+ cells), leading to immune suppression [2]. A higher transcriptional response in the spleen, both in resistant and susceptible lines of chickens at $2 \sim 4$ days after infection (dpi), was reported [3]. Several studies have examined host responses to MDV infection in chicken embryo fibroblasts as well as spleen and liver tissue of chicken by microarray analysis [4-7]. Little is known, however, about transcrip-

\section{KARGER 125}

(c) 2015 S. Karger AG, Base

$0300-5526 / 15 / 0582-0095 \$ 39.50 / 0$

E-Mail karger@karger.com

www.karger.com/int
Aijian Qin, DVM, PhD

Ministry of Education Key Lab for Avian Preventive Medicine

Yangzhou University, No.12 East Wenhui Road

Yangzhou 225009 (PR China)

E-Mail aijian@yzu.edu.cn 
tional responses occurring in the chicken thymus during MDV infection. We found that a latent infection was established at $14 \mathrm{dpi}$ in infected thymuses in our prior research; the expression of most of the genes was reduced or shut down at this stage [8]. We speculated that genes related to immune response and tumor development may exhibit different trends in transcriptional activity in infected chicken thymuses at different time points.

The availability of the chicken genome sequence [9] and commercially available whole-genome microarrays has revolutionized our ability to evaluate host-pathogen interactions [10] and has been applied to the study of host response to MDV [11]. Earlier microarray studies were mainly performed in vitro to investigate the interactions between chicken embryo fibroblasts and HVT or the RB1B strain of MDV $[5,6]$. The differential expressions of host genes were involved in antigen presentation (MHC class I, MHC class II, and $\beta_{2}$-microglobulin) and interferon responses in infected cells $[5,6]$. Recently, some studies have focused on chicken spleen responses to the MDV. They found the expression levels of more than 22 immune-response and related genes were downregulated, while the expression levels of at least 58 genes were increased at 5 dpi (cytolytic infection), compared with age-matched control birds [12]. In comparison, of $73 \mathrm{im}$ mune-response and related genes, 67 genes were downregulated, with only 6 genes having higher expression levels at 15 dpi (latency infection). Many MDV-induced downregulated genes are critical for an effective antiviral immune response. Kano et al. [13] found that the expression of T-cell receptor 1-related genes was upregulated in vaccinated-challenged chickens compared to unvaccinated chickens during the latent phase of infection. However, a comprehensive gene expression in response to MDV infection in the thymuses of chickens at different stages of viral pathogenesis - including the cytolytic, latent, and transformation phases - remains unknown.

In this study, we performed a comprehensive gene expression study using Affymetrix Gene-Chip Chicken Genome Arrays to analyze the host response to infection in chicken thymus tissues at 7, 14, 21, and 28 dpi. Our results revealed a lower transcriptional response at $14 \mathrm{dpi}$ than other time points during MDV infection. Gene ontology (GO) enrichment analysis showed upregulated expressed genes involved in immunity and inflammatory response at $7 \mathrm{dpi}$. Others associated with angiogenesis, cytoskeleton organization, cell adhesion, and signal transduction upregulated at 21 and $28 \mathrm{dpi}$. We experimented with several host genes (e.g. JUN, STAT3, STMN1, and OCM2) associated with tumor development.

\section{Materials and Methods}

\section{Chickens and Virus}

All chickens used in this study were 1-day-old specific pathogen-free white Leghorns obtained from Merial Vital (Laboratory Animal Technology Co., Ltd., Beijing, China). Chickens were housed in an isolation facility at the College of Veterinary Medicine, Yangzhou University. RB1B strains of very virulent MDV were maintained in the laboratory.

\section{Experimental Design}

The experimental work was performed as reported before $[8$, 14]. Briefly, infected and uninfected control birds were kept in separate units with similar environmental conditions. At 7, 14, 21, and 28 days after infection (dpi), 6 chickens ( 3 infected and uninfected control birds each) were sacrificed, and whole thymuses were rapidly excised, rinsed with ice-cold phosphate-buffered saline $(\mathrm{pH}$ 7.4) to remove blood contaminants, and then immediately stored in liquid nitrogen until gene expression analysis.

\section{RNA Extraction and Purification}

The thymus samples were from the same chickens used in previous studies $[8,14]$. Total RNA was extracted using TRIzol Reagent (Life Technologies, Carlsbad, Calif., USA) following the manufacturer's instructions and checked for a RIN number to enable inspection of RNA integrity with an Agilent Bioanalyzer 2100 (Agilent Technologies, Santa Clara, Calif., USA). Qualified total RNA was further purified by an RNeasy Mini Kit (Qiagen GmbH, Germany) and an RNase-Free DNase Set (Qiagen).

\section{RNA Amplification and Labeling, Array Hybridization and}

Data Acquisition

Total RNA was amplified, labeled, and purified using GeneChip 3'IVT Express Kit (Affymetrix, Santa Clara, Calif., USA) following the manufacturer's instructions to obtain biotin-labeled cRNA. Array hybridization and wash was performed using GeneChip ${ }^{\circledR}$ Hybridization and the Wash and Stain Kit (Affymetrix) in the Hybridization Oven 645 (Affymetrix) and Fluidics Station 450 (Affymetrix) by meticulously following the manufacturer's instructions. Slides were scanned by a GeneChip ${ }^{\circledR}$ Scanner 3000 (Affymetrix) and analyzed using Command Console Software 3.1 (Affymetrix) with default settings. Raw data were normalized using a quantile algorithm and Gene Spring Software 11.0 (Agilent Technologies). Genes in which expression was significantly different between the compared groups were chosen based on a log 2 -fold change $\geq 2$ in gene expression, $t$ test $p$ value $<0.05$, and corrected for multiple testing by the Benjamin-Hochberg method. Differentially expressed genes between control and infected groups were identified by a threshold of $\geq 2$-fold change and $p \leq 0.05$.

\section{Bioinformatics Analysis of Microarray Data}

Significantly different genes were determined using GeneSpring GX Software. Gene preliminary screening was conducted using the SBC Analysis System. To highlight the most relevant GO terms associated with a given gene list, we performed GO term enrichment analysis by GOEAST (Gene Ontology Enrichment Analysis Software Toolkit; http://omicslab.genetics.ac.cn/GOEAST/ index.php), a Web-based software toolkit for GO enrichment analysis. The log-transformed expression values (with a base of 2) of normalized microarray data were conducted with gene sets and 
Table 1. Primers used for real-time PCR

\begin{tabular}{|c|c|c|c|c|}
\hline Gene Symbol & $\mathrm{Nu}$ & tide sequence & Product & Reference/accession \\
\hline CD74 & $\begin{array}{l}\text { F: } \\
\text { R: }\end{array}$ & $\begin{array}{l}5^{\prime} \text {-TCAGACCCCAGGAAGACATT-3' } \\
5^{\prime} \text {-CTCAAAATCCTGCCAGTCCA-3' }\end{array}$ & 102 & NM_001001613.1 \\
\hline BLA & $\begin{array}{l}\text { F: } \\
\text { R: }\end{array}$ & $\begin{array}{l}5^{\prime} \text {-GTCATGATCGGCAACTCCAACC-3' } \\
5^{\prime} \text {-TATCGGCGTAGCAGATGAGGAC-3' }\end{array}$ & 118 & NM_001245061.1 \\
\hline BLB2 & $\begin{array}{l}\text { F: } \\
\text { R: }\end{array}$ & $\begin{array}{l}5^{\prime} \text {-GCTGACTGCCACTACCTGA-3' } \\
5^{\prime} \text {-GGCGTTGCTGTTCCAGTAT-3' }\end{array}$ & 159 & NM_001044679.1 \\
\hline TLR2 & $\begin{array}{l}\mathrm{F}: \\
\mathrm{R}:\end{array}$ & $\begin{array}{l}5^{\prime} \text {-GCAACTGGAAAATGTGGGC-3' } \\
5^{\prime} \text {-CGGGCGAATGAAGTCCAAAC-3' }\end{array}$ & 140 & NM_001161650.1 \\
\hline TLR4 & $\begin{array}{l}\mathrm{F}: \\
\mathrm{R}:\end{array}$ & $\begin{array}{l}5^{\prime} \text {-TGACCTACCCATCGGACACT-3' } \\
5^{\prime} \text {-CTCAGGGCATCAAGGTCTCC-3' }\end{array}$ & 171 & NM_001030693.1 \\
\hline CD8B & $\begin{array}{l}\text { F: } \\
\text { R: }\end{array}$ & $\begin{array}{l}5^{\prime} \text {-AACAAACAACAGCACAGAGA-3' } \\
5^{\prime} \text {-CGGACTGGAAAATAGCAAGA-3' }\end{array}$ & 115 & NM_205247.2 \\
\hline CD8A & $\begin{array}{l}\mathrm{F}: \\
\mathrm{R}:\end{array}$ & $\begin{array}{l}5^{\prime} \text {-TCAGAGCCAGGAACAAGCA-3' } \\
5^{\prime} \text {-CAGGCATCCCATTTGGAG-3' }\end{array}$ & 178 & NM_205235.1 \\
\hline VAV3 & $\begin{array}{l}\text { F: } \\
\text { R: }\end{array}$ & $\begin{array}{l}5^{\prime} \text {-ACCCGCAGATGTCCCAGTT-3' } \\
5^{\prime} \text {-CAATAGGAGTGCGGGAAAG-3' }\end{array}$ & 174 & NM_206863.2 \\
\hline GADD45A & $\begin{array}{l}\text { F: } \\
\text { R: }\end{array}$ & $\begin{array}{l}5^{\prime} \text {-GCTGCGAGAACGACATCA-3' } \\
5^{\prime} \text {-GGGGATTCGTGACCAAGAC-3' }\end{array}$ & 123 & NM_001044678.1 \\
\hline CASP6 & $\begin{array}{l}\text { F: } \\
\text { R: }\end{array}$ & $\begin{array}{l}5^{\prime} \text {-CGTGGGACTTTGGCAGACA-3' } \\
5^{\prime} \text {-TGTAGTCATCCCGAGAGGC-3' }\end{array}$ & 133 & NM_204726.1 \\
\hline $\mathrm{RB} 1$ & $\begin{array}{l}\text { F: } \\
\text { R: }\end{array}$ & $\begin{array}{l}5^{\prime} \text {-TGCGACCTCACAAACACAGA-3' } \\
5^{\prime} \text {-CAGGTCAGGATGTTCGGAG-3' }\end{array}$ & 130 & NM_204419.1 \\
\hline $\mathrm{p} 21$ & $\begin{array}{l}\text { F: } \\
\text { R: }\end{array}$ & $\begin{array}{l}5^{\prime} \text {-CGAGCAGATCCAGAACGACT-3' } \\
5^{\prime} \text {-GCGTCTCGGTCTCGAAGTT-3' }\end{array}$ & 92 & NM_204396.1 \\
\hline VIM & $\begin{array}{l}\mathrm{F}: \\
\mathrm{R}:\end{array}$ & $\begin{array}{l}\text { 5'-CAACACGGAGTTCAAGGCGA-3' } \\
5^{\prime} \text {-GATGTAGTTGGCGAAGCGGT-3' }\end{array}$ & 79 & NM_001048076.1 \\
\hline NPM1 & $\begin{array}{l}\text { F: } \\
\text { R: }\end{array}$ & $\begin{array}{l}5^{\prime} \text {-GGTTACATTAGGGGCTGG-3' } \\
5^{\prime} \text {-GTTGCCTTCGTAGTCCAGTG-3' }\end{array}$ & 73 & NM_205267.1 \\
\hline HSP90AA1 & $\begin{array}{l}\text { F: } \\
\text { R: }\end{array}$ & $\begin{array}{l}5^{\prime} \text {-TTTGACTGACCCGAGCA-3' } \\
5^{\prime} \text {-TTGGTCATCCCTATGCCG-3' }\end{array}$ & 110 & NM_001109785.1 \\
\hline HIF1A & $\begin{array}{l}\mathrm{F}: \\
\mathrm{R}:\end{array}$ & $\begin{array}{l}5^{\prime} \text {-CGTTCCTCAGTCGTCACAGT-3' } \\
5^{\prime} \text {-ACCTGCCCTTTCGTGAACAT-3' }\end{array}$ & 178 & NM_204297.1 \\
\hline p53 & $\begin{array}{l}\mathrm{F}: \\
\mathrm{R}:\end{array}$ & $\begin{array}{l}5^{\prime} \text {-GTTACCACGACGACGAGACC-3' } \\
5^{\prime} \text {-ACAGCACCGTGGTACAGTCA-3' }\end{array}$ & 90 & NM_205264.1 \\
\hline ANXA1 & $\begin{array}{l}\mathrm{F}: \\
\mathrm{R}:\end{array}$ & $\begin{array}{l}5^{\prime} \text {-AAAACTGCCTGACTGCCCTT-3' } \\
5^{\prime} \text {-TTCCACTCCCCTTCATTGCC-3 }\end{array}$ & 90 & NM_206906.1 \\
\hline $18 \mathrm{~S}$ & $\begin{array}{l}\text { F: } \\
\text { R: }\end{array}$ & $\begin{array}{l}5^{\prime} \text {-TCAGATACCGTCGTAGTTCC-3' } \\
5^{\prime} \text {-TTCCGTCAATTCCTTTAAGTT-3' }\end{array}$ & 154 & {$[17]$} \\
\hline
\end{tabular}














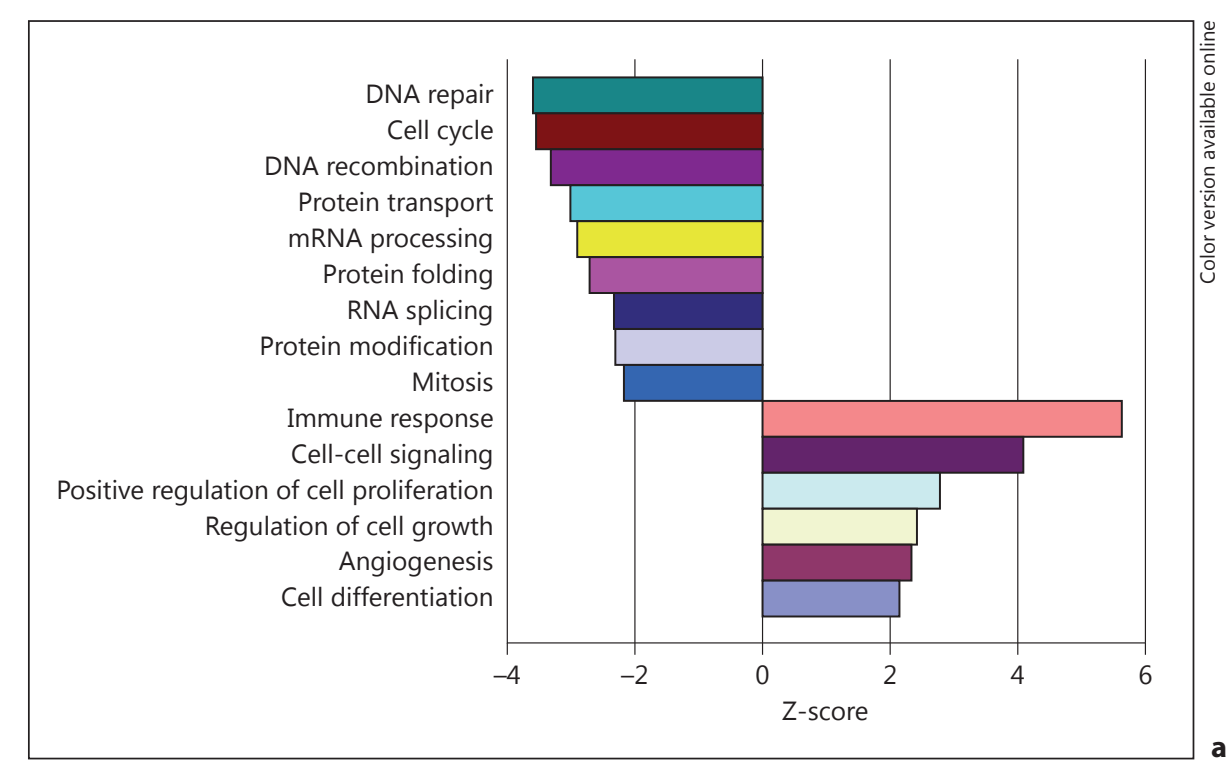

Fig. 1. Dysregulated biological pathways relative to uninfected birds by GAzer. (Zscore $<0$, downregulated; Z-score $>0$, upregulated). a Map of GAzer to identify the most dysregulated biological pathways. b Z-score and $\mathrm{p}$ value of dysregulated pathway.

\begin{tabular}{|lll|}
\hline Name & Z-score & $\mathrm{p}$ \\
\hline Immune response & 5.62313 & 0.00000002 \\
Cell-cell signaling & 4.08641 & 0.00004381 \\
Positive regulation of cell proliferation & 2.78731 & 0.00501482 \\
Regulation of cell growth & 2.42919 & 0.01513276 \\
Angiogenesis & 2.33298 & 0.01964921 \\
Cell differentiation & 2.13658 & 0.03263253 \\
DNA repair & -3.61924 & 0.00029547 \\
Cell cycle & -3.32591 & 0.00034175 \\
DNA recombination & -3.32591 & 0.00088129 \\
Protein transport & -3.02015 & 0.00252648 \\
mRNA processing & -2.92245 & 0.00347289 \\
Protein folding & -2.72142 & 0.00650017 \\
RNA splicing & -2.36233 & 0.0181603 \\
Protein modification & -2.32602 & 0.02001723 \\
Mitosis & -2.19131 & 0.0284293 \\
\hline
\end{tabular}

GO analysis through use of the Gazer [15] (http://expressome.kobic.re.kr/GAzer/index.faces). GAzer is a Web-based integrated tool. The basic idea of gene set analysis is to compare two groups by looking at changes in sets of genes, rather than looking at the individual gene level. Therefore, this type of analysis compensates for the fact that small changes not seen at the gene level are often detected when the gene set as a whole is examined. The predicted gene interaction networks among differentially expressed genes found in this study were analyzed by STRING (Search Tool for the Retrieval of Interacting Genes/Proteins; http://string-db.org/) [16].

\section{Real-Time PCR Verification}

The expression of selected genes was verified by real-time PCR (7500 Real-Time PCR System, ABI). Primers were designed and synthesized by Shenergy Biocolor Bioscience and Technology Company (Shanghai, China; primers listed in table 1, $18 \mathrm{~S}$ refer- enced to [17]). Total RNA was prepared from thymuses using the AxyPrep $^{\text {TM }}$ Multisource Total RNA Miniprep Kit (AXYGEN, USA). $1 \mu \mathrm{g}$ of total RNA was reverse-transcribed into first-strand cDNA using PrimeScript RT Master Mix (TaKaRa, USA) following the manufacturer's instructions, and synthesized cDNA was diluted 1:10 with nuclease-free water. $1 \mu$ l of diluted cDNA, 400 nM primers, and $10 \mu \mathrm{l}$ of SYBR Green Master Mix were used for real-time PCR in a final volume of $20 \mu \mathrm{l}$. The amplification conditions were $95^{\circ} \mathrm{C}$ for $30 \mathrm{~s}$, followed by 40 cycles of $95^{\circ} \mathrm{C}$ for $5 \mathrm{~s}$, and then $60^{\circ} \mathrm{C}$ for $34 \mathrm{~s}$. Dissociation curves were generated to analyze individual PCR products after 40 cycles. Gene expression was normalized against the expression of chicken $18 \mathrm{~S}$ mRNA. The analyses of relative gene expression data were performed by the $2^{-\Delta \Delta C T}$ method [18]. Data were compared with Student's t test by the statistical package for social sciences (version 16.0). Genes showing FC values above 2 or below -2 and an unpaired t test $p<0.05$ were defined as significantly changed. 
Table 4. Validation of microarray results by real-time PCR

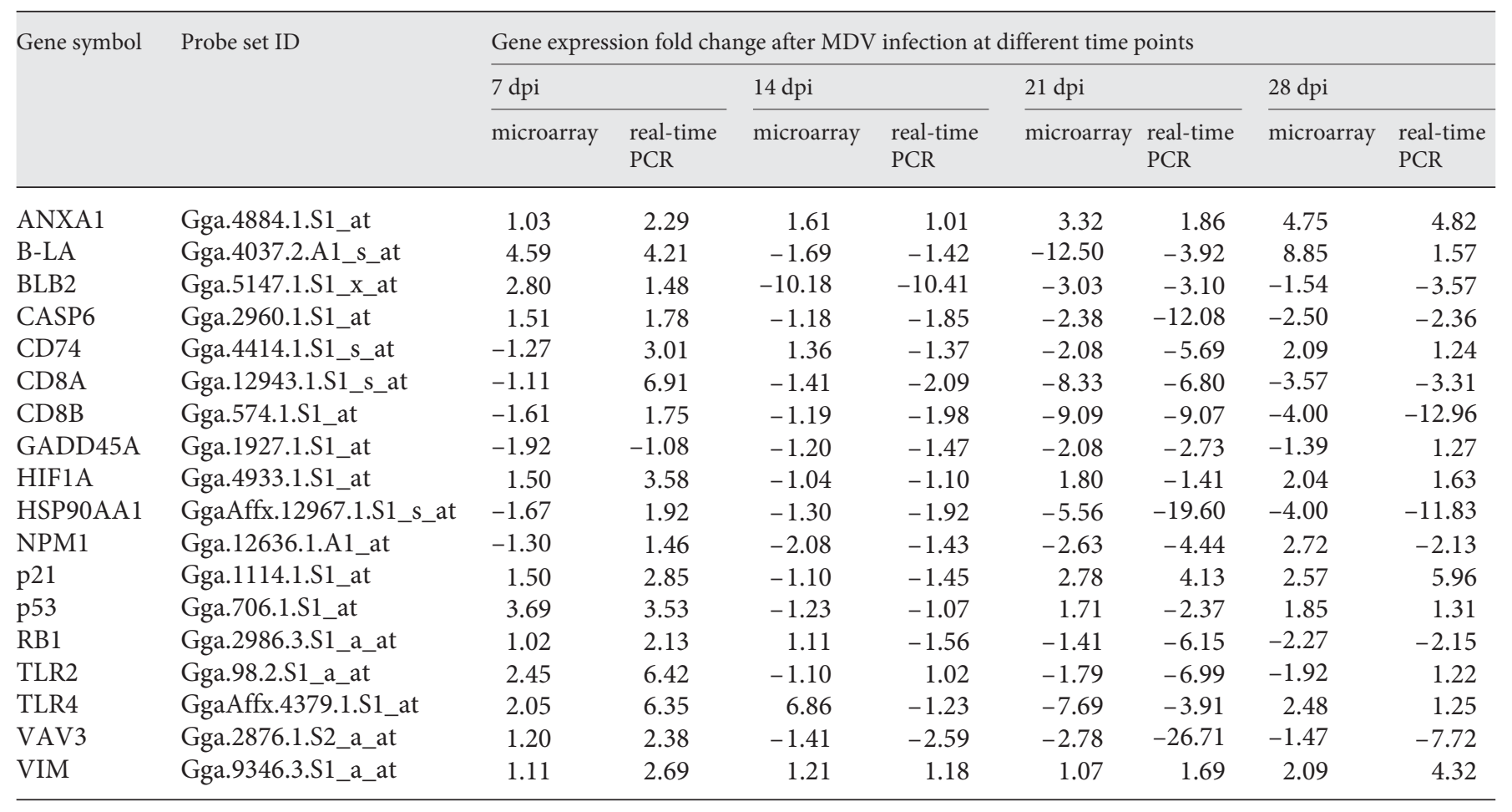

\section{Results}

\section{Chicken Thymus Responses to MDV Infection}

The number of differentially expressed genes with 2 -fold or higher changes (see online suppl. file 1; see www.karger.com/doi/10.1159/000370069 for all online suppl. material) are as follows: 1,250 genes (7 dpi), 834 genes (14 dpi), 1,958 (21 dpi), and 2,306 genes (28 dpi). We found that genes involved in the immune response upregulated at $7 \mathrm{dpi}$ included MHC classes I and II as well as type II interferons, some interleukins and interleukin receptors (IL1- $\beta$, IL-6, IL-8, IL-15, IL-18, IL18R1, IL21R, and IL22RA1). We also found interferon response [e.g. the signaling molecule interferon regulatory factor 1 (IRF1), IRF7, and IRF10]. In addition, several genes associated with innate immune were upregulated, including the Toll-like receptors TLR2, TLR3, TLR4, TLR6, TLR7, and TLR15, and the chemokines CCL1, CCL4, and CCL19. In contrast, the genes involved in tumor development and metastasis were upregulated at 21 and 28 dpi in infected thymuses. These genes include jun oncogene (JUN), v-src sarcoma viral oncogene, vascular endothelial growth factor A, IRF4, signal transducer and activator of transcription 3 (STAT3), and wingless-type MMTV integration site family, member 5A. These find- ings suggest that MDV-activated $\mathrm{T}$ cells in late infection in thymuses induce the activated transformed $\mathrm{T}$ cells to develop cancer.

\section{Analysis of Differentially Expression Genes}

In order to determine which biological process was altered during MDV infection, the microarray data (online suppl. file 1) were further analyzed using GOEAST to determine GO term enrichment. Tables 2 and 3 show the biological process which was significantly $(\mathrm{p}<0.05)$ affected during the host responses to MDV infection. We found the upregulated expression genes involved in immune and inflammatory response at $7 \mathrm{dpi}$. Angiogenesis, cytoskeleton organization, cell adhesion, and signal transduction was shown at 21 and $28 \mathrm{dpi}$. The overall expression level of host genes at four stages was analyzed by GAzer. Upregulated biological processes in infected birds included cell proliferation, angiogenesis, and immune response (fig. 1). Other biological processes including cell cycle, mitosis, mRNA processing, protein folding, modification, and transport were downregulated.

\section{Real-Time PCR Validation of Array Data}

To confirm the microarray data, real-time PCR was performed on 18 selected genes. Fold change was calcu- 


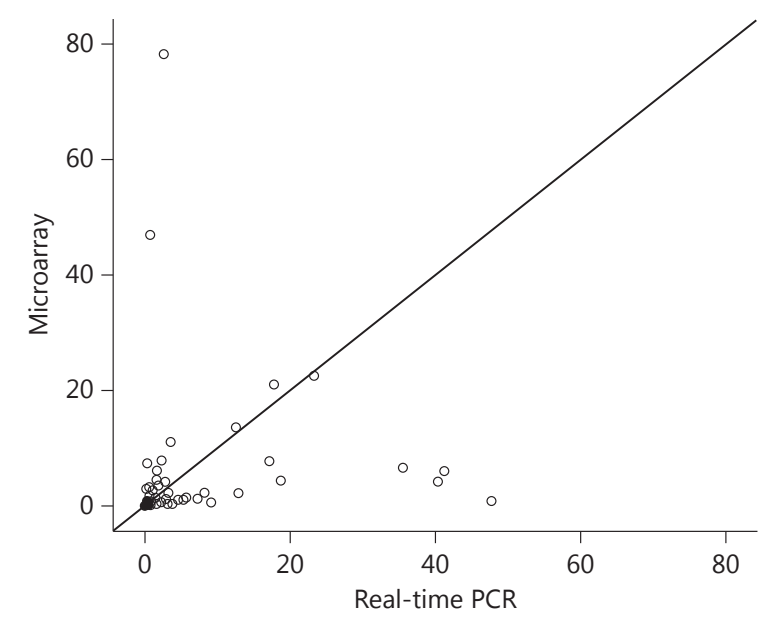

Fig. 2. Scatter plots of microarray and real-time PCR data; the $x$ axis and $y$-axis represent the values of 2 -fold changes.

lated using the $2^{-\Delta \Delta C T}$ method and expression values which were normalized against the expression of $18 \mathrm{~S}$. In table 4 , the negative values suggest the fold change is $<1$; the raw data of fold changes were transformed based on a 2 -fold change and then made into a scatter plot (fig. 2). We found that the real-time PCR data were similar to the observations using the microarray (table 4; fig. 2). A correlation coefficient between real-time PRC data and microarray observations is $0.831(\mathrm{p}=0.00061)$. Thus, the PCR data supported the microarray results.

\section{Discussion}

\section{Antiviral Innate and Adaptive Immune Response}

We found that an induced innate response has been established at $7 \mathrm{dpi}$, in which chemokines, proinflammatory cytokines and Toll-like receptors were activated in infected thymuses. The expression of some chemokines (e.g. CCL1 and CCL4), interleukins (e.g. IL1- $\beta$, IL-6, IL-8, and IL-18) and interleukin receptors (e.g. IL18R1) as well as genes involved in the interferon response (such as IRF1, IRF7, and IRF10) was upregulated. It has been found that MDV infection leads to the upregulation of TLR3 and TLR15 in chicken spleen tissues at 5 dpi and downregulation of TLR5 in liver tissues $[4,12]$. TLRs play a key role in the innate immune system and they recognize molecules that are broadly shared by pathogens [19, 20]. In this study, TLR2, TLR3, TLR4, TLR6, TLR7, and
TLR15 were all significantly upregulated during the early infection with MDV. Some of them then obviously downregulated at $21 \mathrm{dpi}$ (online suppl. file 1). One, at expression level of TLR2, was further verified by real-time PCR (table 3). Downregulation of TLR will interfere with interactions between the receptor molecule and the viruses like other herpesviruses $[21,22]$, perhaps because the host cannot clear MDV-infected cells.

Likewise, adaptive immune responses were also altered by MDV. Several genes involved in antigen process and presentation, such as CD8, CD4, and MHC II, were decreased in infected chicken thymus after $7 \mathrm{dpi}$. These could be caused by downregulation of MHC-mediated antigen presentation. These results were consistent with other reports $[12,23,24]$. Furthermore, we found that CD28, a costimulatory molecule that is essential for the activation of $\mathrm{T}$ cells, was severely decreased. This may be a potential mechanism of the immune suppressive/evasive activities of MDV. However, MHC class I molecules were upregulated in the chicken thymuses infected with MDV at different stages. This phenomenon needs to be investigated further in the future.

\section{Cell Cycle and Apoptosis}

$\mathrm{GO}$ enrichment analysis of different gene expressions indicated that apoptosis and cell cycle were downregulated during the host response to infection with MDV (fig. 2). Apoptosis has been shown to be a common host cell response to viral infection [25], which is advantageous for the host as it eliminates virus-infected cells. Current evidence indicates that MDV has evolved multiple mechanisms to thwart this cellular response to protect cells against apoptosis $[26,27]$. One of the latest discoveries is that the Meq oncoprotein of MDV inhibited p53-dependent transcription and apoptosis by interacting directly with p53 [26]. In our study, we further found that several genes of $\mathrm{p} 53$-dependent apoptosis pathway including CHEK2, CYCS, APAF1, and PERP were downregulated in infected thymuses at 21 and $28 \mathrm{dpi}$. Earlier studies showed that Bcl-2 blocks a caspase-dependent pathway of apoptosis in HSV-1 infected cells for virus replication [28]. The downregulated expression of Bcl-2 was found in our study. Ohashi et al. [29] also found that the expression of Bcl-2 was downregulated in both CD4+ and CD8+ T cells prepared from MDV-infected chickens at 3 weeks after infection. No Bcl-2 transcript was detected in MD tumor-derived MSB1 and MTB1 cell lines. These results suggest that MDV-inhibited apoptosis makes itself grow in the cells and then transforms them. 


\begin{tabular}{|c|c|}
\hline Gene & Description \\
\hline HIF1A & $\begin{array}{l}\text { hypoxia-inducible factor } 1 \text {, alpha-subunit (basic helix-loop-helix } \\
\text { transcription factor) }\end{array}$ \\
\hline HSP90AA1 & heat shock protein 90 kDa alpha (cytosolic), class A member 1 \\
\hline IRF4 & interferon regulatory factor 4 \\
\hline JUN & jun oncogene \\
\hline MAFB & v-maf musculoaponeurotic fibrosarcoma oncogene homolog B \\
\hline OCM2 & oncomodulin 2 \\
\hline SRC & v-src sarcoma viral oncogene \\
\hline STAT3 & $\begin{array}{l}\text { signal transducer and activator of transcription } 3 \text { (acute-phase } \\
\text { response factor) }\end{array}$ \\
\hline STMN1 & stathmin 1 \\
\hline TCBA1 & T-cell lymphoma breakpoint-associated target 1 \\
\hline TIAM1 & T-cell lymphoma invasion and metastasis 1 \\
\hline TP53 & tumor protein 53 \\
\hline TRAT1 & T-cell receptor-associated transmembrane adaptor 1 \\
\hline VEGFA & vascular endothelial growth factor $A$ \\
\hline WNT5A & wingless-type MMTV integration site family, member 5A \\
\hline
\end{tabular}

Fig. 3. The main differently expressed host genes involved in MDV transformation and their interaction network based on the STRING database. a Genes involved in angiogenesis, cell proliferation, apoptosis, cell immune-related signaling pathways, and MDV transformation. $\mathbf{b}$ Network of genegene interactions based on the STRING database.

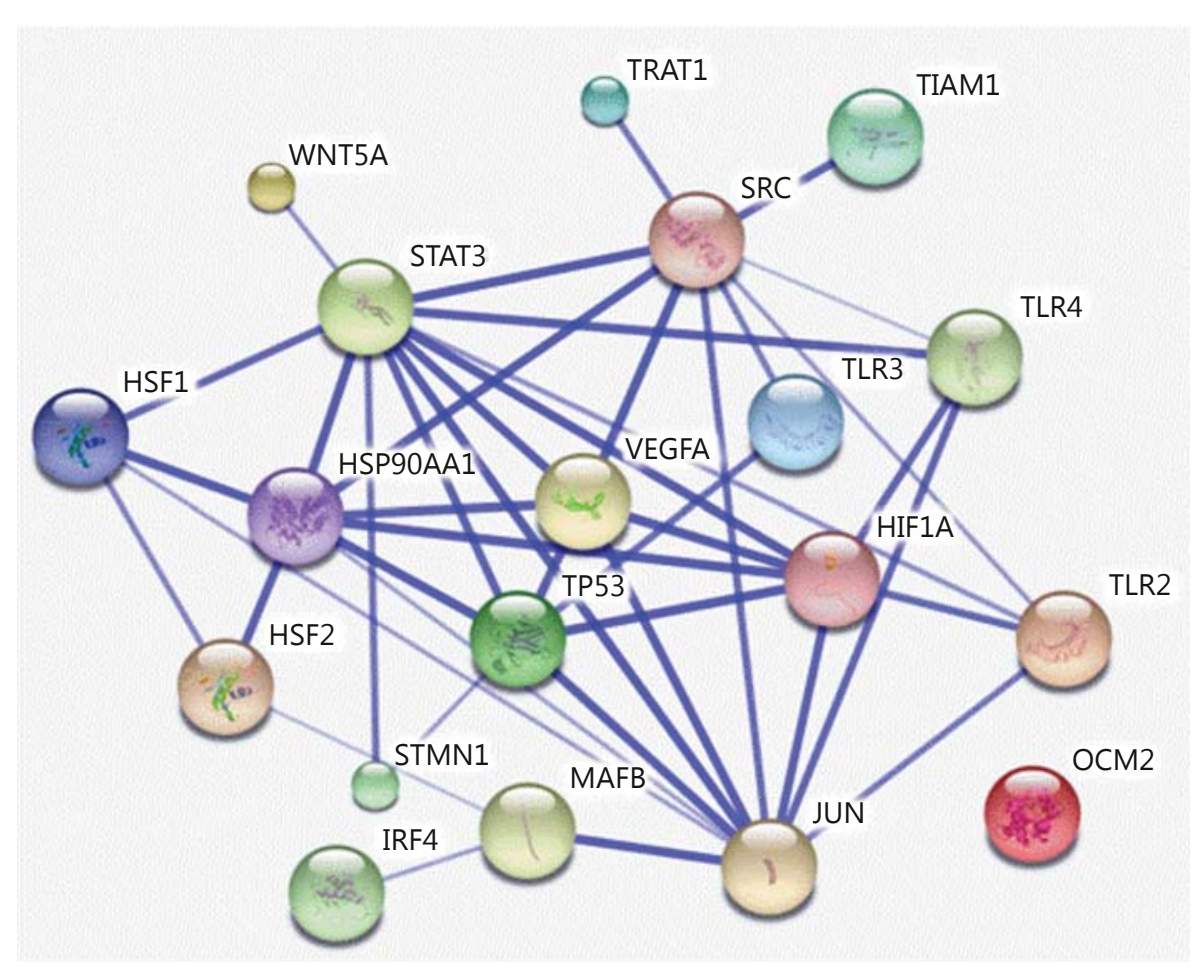

Herpesviruses elicit a cell cycle arrest by virus-encoded proteins to block cellular DNA replication and support efficient viral replication [30]. For MDV, it is known that Meq can bind to several factors that are involved in cell cycle control, including CDK2, p53, and RB. However, the mechanism of cell cycle arrest induced by MDV remains unclear. Our microarray analysis results show that thymuses infected with MDV induced upregulated expression of p21 and GADD45, which are known down- stream targets of $\mathrm{p} 53$. Corresponding to these changes, CDK6, cyclin D, cyclin E, CDC2, and cyclin B, which are critical regulators of G1 and G2 cell cycle arrest, were mainly downregulated at 21 and $28 \mathrm{dpi}$. Upregulation expression of p21, an important cell cycle arrest factor, was further verified by real-time PCR analysis. The increased expression of p21 in infected cells was also found in other herpesviruses [31, 32]. 


\section{Potential Host Genes Involved in MDV}

\section{Transformation}

There is little literature on the potential host genes involved in MDV transformation in chicken thymuses. In this study, we found the expression of genes involved in angiogenesis, cell proliferation, apoptosis, and cell immune-related signaling pathways (e.g. JAK-STAT, MAPK, JUN, and Wnt pathways) was upregulated at 21 and 28 dpi. We listed some tumor-related genes involved in MDV transformation (fig. 3a). According to the network of these genes interactions (fig. 3b), some genes such as STAT3 and JUN can broadly interact with other genes.

The JAK-STAT signaling pathway is involved in regulating cytokine-dependent gene expressions. Dysregulation of this pathway is associated with cellular transformation [33, 34]. Chen et al. [35] and Vaysberg et al. [36] verified that JAK-STAT signaling plays a role in EBVassociated malignancies. In this study, we observed upregulation expressions of the STAT3 gene in infected thy- muses with MDV. Activation of STAT3 occurs in many tumors and is correlated with transformation and antiapoptotic effects in malignancies [33]. The increased expression of STAT3 induced by MDV might be contributed to MDV transformation. JUN pathways play a critical role in malignant transformation. It could be activated in infected cells by herpesviruses such as EBV and KSHV [37-39]. The expression of JUN was also found to be upregulated in infected thymuses. Levy et al. [40] confirmed that Meq can transform chicken cells via the Jun pathway.

\section{Acknowledgement}

This research was supported by the National Natural Science Foundation of China (31272560, 31472192), the Major Basic Research Department of the Natural Science Foundation of Jiangsu Higher Education Institutions of China (Grant No. 12KJA23001), and the Priority Academic Program Development of Jiangsu Higher Education Institutions.

\section{References}

1 Biggs PM: The history and biology of Marek's disease virus. Curr Topics Microbiol Immunol 2001;255:1-24

2 Barrow A, Venugopal K: Molecular characteristics of very virulent European MDV isolates. Acta Virol 1999;43:90-93.

3 Smith J, Sadeyen JR, Paton IR, Hocking PM, Salmon N, Fife M, Nair V, Burt DW, Kaiser P: Systems analysis of immune responses in Marek's disease virus-infected chickens identifies a gene involved in susceptibility and highlights a possible novel pathogenicity mechanism. J Virol 2011;85:11146-11158.

4 Chen C, Li H, Xie Q, Shang H, Ji J, Bai S, Cao Y, Ma Y, Bi Y: Transcriptional profiling of host gene expression in chicken liver tissues infected with oncogenic Marek's disease virus. J Gen Virol 2011;92:2724-2733.

5 Karaca G, Anobile J, Downs D, Burnside J, Schmidt CJ: Herpesvirus of turkeys: microarray analysis of host gene responses to infection. Virology 2004;318:102-111.

6 Morgan RW, Sofer L, Anderson AS, Bernberg EL, Cui J, Burnside J: Induction of host gene expression following infection of chicken embryo fibroblasts with oncogenic Marek's disease virus. J Virol 2001;75:533-539.

7 Sarson AJ, Abdul-Careem MF, Zhou H, Sharif S: Transcriptional analysis of host responses to Marek's disease viral infection. Viral Immunol 2006;19:747-758.
$8 \mathrm{Hu}$ X, Qin A, Miao J, Xu W, Yu C, Qian K, Shao H: Transcriptional profile of Marek's disease virus genes in chicken thymus during different phases of MDV infection. Arch Virol 2013;158:1787-1793.

9 International Chicken Genome Sequencing Consortium: Sequence and comparative analysis of the chicken genome provide unique perspectives on vertebrate evolution. Nature 2004;432:695-716.

10 Crowley TM, Haring VR, Burggraaf S, Moore RJ: Application of chicken microarrays for gene expression analysis in other avian species. BMC Genomics 2009;10(suppl 2):S3.

11 Haq K, Brisbin JT, Thanthrige-Don N, Heidari M, Sharif S: Transcriptome and proteome profiling of host responses to Marek's disease virus in chickens. Vet Immunol Immunopathol 2010;138:292-302.

12 Heidari M, Sarson AJ, Huebner M, Sharif S, Kireev D, Zhou H: Marek's disease virus-induced immunosuppression: array analysis of chicken immune response gene expression profiling. Viral Immunol 2010;23:309-319.

13 Kano R, Konnai S, Onuma M, Ohashi K: Microarray analysis of host immune responses to Marek's disease virus infection in vaccinated chickens. J Vet Med Sci 2009;71:603-610.

14 Hu X, Qin A, Qian K, Shao H, Yu C, Xu W, Miao J: Analysis of protein expression profiles in the thymus of chickens infected with Marek's disease virus. Virol J 2012;9:256.

15 Kim SB, Yang S, Kim SK, Kim SC, Woo HG, Volsky DJ, Kim SY, Chu IS: GAzer: gene set analyzer. Bioinformatics 2007;23:1697-1699.
16 Szklarczyk D, Franceschini A, Kuhn M, Simonovic M, Roth A, Minguez P, Doerks T, Stark M, Muller J, Bork P, Jensen LJ, von Mering C: The STRING database in 2011: functional interaction networks of proteins, globally integrated and scored. Nucleic Acids Res 2011; 39:D561-D568.

17 Li YP, Bang DD, Handberg KJ, Jorgensen $\mathrm{PH}$, Zhang MF: Evaluation of the suitability of six host genes as internal control in real-time RTPCR assays in chicken embryo cell cultures infected with infectious bursal disease virus. Vet Microbiol 2005;110:155-165.

18 Livak KJ, Schmittgen TD: Analysis of relative gene expression data using real-time quantitative PCR and the $2^{-\Delta \Delta C_{\mathrm{T}}}$ method. Methods 2001;25:402-408.

19 Kang JY, Lee JO: Structural biology of the Toll-like receptor family. Annu Rev Biochem 2011;80:917-941.

20 West AP, Koblansky AA, Ghosh S: Recognition and signaling by Toll-like receptors. Annu Rev Cell Dev Biol 2006;22:409-437.

21 Gankovskaia OA, Gankovskaia LV, Somova O, Zverev VV: Toll-like receptors recognizing ligands of herpesvirus (in Russian). Zh Mikrobiol Epidemiol Immunobiol 2009;108-111.

22 Liu X, Fitzgerald K, Kurt-Jones E, Finberg R, Knipe DM: Herpesvirus tegument protein activates NF-kappaB signaling through the TRAF6 adaptor protein. Proc Natl Acad Sci USA 2008;105:11335-11339. 
23 Morimura T, Ohashi K, Kon Y, Hattori M, Sugimoto C, Onuma M: Apoptosis and CD8down-regulation in the thymus of chickens infected with Marek's disease virus. Arch Virol 1996;141:2243-2249.

24 Thanthrige-Don N, Read LR, Abdul-Careem MF, Mohammadi H, Mallick AI, Sharif S: Marek's disease virus influences the expression of genes associated with IFN-gamma-inducible MHC class II expression. Viral Immunol 2010;23:227-232.

25 Young LS, Dawson CW, Eliopoulos AG: Viruses and apoptosis. Br Med Bull 1997;53: 509-521.

26 Deng X, Li X, Shen Y, Qiu Y, Shi Z, Shao D, Jin Y, Chen H, Ding C, Li L, Chen P, Ma Z: The Meq oncoprotein of Marek's disease virus interacts with p53 and inhibits its transcriptional and apoptotic activities. Virol J 2010;7:348.

27 Subramaniam S, Johnston J, Preeyanon L, Brown CT, Kung HJ, Cheng HH: Integrated analyses of genome-wide DNA occupancy and expression profiling identify key genes and pathways involved in cellular transformation by Marek's disease oncoprotein, Meq. J Virol 2013;87:9016-9029.

28 Galvan V, Brandimarti R, Munger J, Roizman B: Bcl-2 blocks a caspase-dependent pathway of apoptosis activated by herpes simplex virus 1 infection in HEp-2 cells. J Virol 2000;74: 1931-1938.
29 Ohashi K, Morimura T, Takagi M, Lee SI, Cho KO, Takahashi H, Maeda Y, Sugimoto C, Onuma M: Expression of bcl-2 and bcl-x genes in lymphocytes and tumor cell lines derived from MDV-infected chickens. Acta Virol 1999;43:128-132.

30 Flemington EK: Herpesvirus lytic replication and the cell cycle: arresting new developments. J Virol 2001;75:4475-4481.

31 Izumiya Y, Lin SF, Ellison TJ, Levy AM, Mayeur GL, Izumiya C, Kung HJ: Cell cycle regulation by Kaposi's sarcoma-associated herpesvirus K-bZIP: direct interaction with $\mathrm{cy}$ clin-CDK2 and induction of G1 growth arrest. J Virol 2003;77:9652-9661.

32 Li L, Gu B, Zhou F, Chi J, Wang F, Peng G, Xie F, Qing J, Feng D, Lu S, Yao K: Human herpesvirus 6 suppresses $\mathrm{T}$ cell proliferation through induction of cell cycle arrest in infected cells in the G2/M phase. J Virol 2011; 85:6774-6783.

33 Kisseleva T, Bhattacharya S, Braunstein J, Schindler CW: Signaling through the JAK/ STAT pathway, recent advances and future challenges. Gene 2002;285:1-24.

34 O'Shea JJ, Gadina M, Schreiber RD: Cytokine signaling in 2002: new surprises in the Jak/ Stat pathway. Cell 2002;109(suppl):S121S131.

35 Chen H, Lee JM, Wang Y, Huang DP, Ambinder RF, Hayward SD: The Epstein-Barr virus latency BamHI-Q promoter is positively regulated by STATs and Zta interference with JAK/STAT activation leads to loss of BamHIQ promoter activity. Proc Natl Acad Sci USA 1999;96:9339-9344.
36 Vaysberg M, Lambert SL, Krams SM, Martinez OM: Activation of the JAK/STAT pathway in Epstein Barr virus+-associated posttransplant lymphoproliferative disease: role of interferon-gamma. Am J Transplant 2009; 9:2292-2302.

37 Kutz H, Reisbach G, Schultheiss U, Kieser A: The c-Jun N-terminal kinase pathway is critical for cell transformation by the latent membrane protein 1 of Epstein-Barr virus. Virology 2008;371:246-256.

38 Qin D, Feng N, Fan W, Ma X, Yan Q, Lv Z, Zeng Y, Zhu J, Lu C: Activation of PI3K/AKT and ERK MAPK signal pathways is required for the induction of lytic cycle replication of Kaposi's sarcoma-associated herpesvirus by herpes simplex virus type 1 . BMC Microbiol 2011;11:240.

39 Roberts ML, Cooper NR: Activation of a rasMAPK-dependent pathway by Epstein-Barr virus latent membrane protein 1 is essential for cellular transformation. Virology 1998; 240:93-99.

40 Levy AM, Gilad O, Xia L, Izumiya Y, Choi J, Tsalenko A, Yakhini Z, Witter R, Lee L, Cardona CJ, Kung HJ: Marek's disease virus Meq transforms chicken cells via the v-Jun transcriptional cascade: a converging transforming pathway for avian oncoviruses. Proc Natl Acad Sci USA 2005;102:14831-14836. 